\title{
A study of intimate partner violence among females attending a Teaching Hospital out-patient department
}

\author{
K.A.L.A.Kuruppuarachchi, L.T.Wijeratne, G.D.S.S.K.Weerasinghe, M.U.P.K.Peris, S.S.Williams
}

\section{Background}

Intimate partner violence (IPV) is considered a public health problem with physical and psychological consequences.

\section{Aims}

To describe the prevalence of IPV among married females attending the out-patient department of North Colombo Teaching Hospital and their attitude towards abuse.

\section{Methods}

A pre-tested self-administered questionnaire on physical, verbal, sexual and emotional abuse was given to the first 50 consenting married females attending the out-patient department on each day for five consecutive days. Confidentiality of responses was assured and adequate privacy was provided for the questionnaires to be completed.

\section{Results}

Of the 242 participants 98(40.5\%) reported some form of abuse by their male partner. Prevalence of abuse reported was physical abuse $19 \%$, verbal abuse $23 \%$, emotional abuse $23 \%$ and sexual abuse $7 \%$. A quarter (26.9\%) of those inflicted physical violence sought medical treatment for the injuries but only two of them divulged the reason for the injury to medical staff. More than three quarters (79\%) of those abused were in the relationship for more than ten years. The majority of the females surveyed believed that violence by the male partner should be tolerated.

\section{Conclusions}

IPV is a common problem that is poorly divulged to medical personnel. Attitudes regarding IPV have to be changed in order to reduce abuse significantly.

SL J Psychiatry 2010; 1 (2):60-63

\section{Introduction}

The United Nations' Declaration of Violence Against Women, defines violence against women as an act of gender based violence that results in or is likely to result in physical, sexual or psychological harm to women. The commonest form of violence perpetrated on women is intimate partner violence (IPV). Intimate partner violence is highly prevalent globally $(1,2)$. A WHO multi-country survey on women's health showed that between $15 \%$ and $71 \%$ of ever partnered women have experienced physical or sexual violence by an intimate partner at some point in their lives (3). However inter-regional and intra-regional variations in prevalence accounts for the wide range reported in this study.

In Sri Lanka too IPV is recognized as a matter of concern. The legislative framework to address violence in the home has been strengthened (4). However published data regarding its prevalence is sparse.

The objective of this study was to assess the prevalence of IPV among women attending an out-patient department in a Teaching Hospital. We also studied the basic demographic characteristics of those abused and their response to the abuse they experienced.

\section{Methods}

The study was conducted at the Out Patient Department (OPD) of North Colombo Teaching Hospital, located in a semi urban area close to the capital of Sri Lanka. The first 50 consenting married females attending the OPD on five consecutive days were included in the study. A self administered structured questionnaire in Sinhala with questions covering the socio- demographic status, level of education, details regarding the relationship with the spouse and presence of substance abuse in the spouse, was administered. Questions were asked about physical, verbal, emotional and sexual abuse.

We defined physical abuse as assault of any nature by the husband and verbal abuse as the use of harsh words. Deliberately hurting feelings was considered emotional abuse and sexual abuse was defined as being forced to engage in a sexual act with their husband against their wishes.

All the women irrespective of abuse status were asked of their views on abuse. Details pertaining to need for medical attention as a result of abuse and whether they had confided in a health worker regarding the incident was recorded. Confidentiality of the information obtained was assured and enough privacy was provided to answer the questions. Those distressed by the abuse were referred to appropriate services. The data was entered in an Excel worksheet and chi square comparisons were done where appropriate.

\section{Results}

Out of the 250 questionnaires distributed $242(96 \%)$ were filled and returned. The majority $(69.2 \%)$ of 
Table- Attitude towards different forms of abuse.

\begin{tabular}{|lllr|}
\hline Type of abuse & $\begin{array}{l}\text { Abused } \\
\mathrm{n}(\%)\end{array}$ & $\begin{array}{l}\text { Non-abused } \\
\mathrm{n}(\%)\end{array}$ & $\begin{array}{r}\text { Total } \\
\mathrm{n}(\%)\end{array}$ \\
\hline Physical abuse & & & \\
Should not be tolerated at all & $21(22.8)$ & $28(24.3)$ & $49(23.7)$ \\
Should be tolerated sometimes & $43(46.7)$ & $65(56.5)$ & $108(52.2)$ \\
Should be tolerated all the time & $28(30.5)$ & $22(19.1)$ & $50(24.2)$ \\
\hline Verbal abuse & & & \\
Should not be tolerated at all & $17(19.1)$ & $24(21.2)$ & $41(20.3)$ \\
Should be tolerated sometimes & $51(57.3)$ & $66(58.4)$ & $117(57.9)$ \\
Should be tolerated all the time & $21(23.6)$ & $23(20.4)$ & $44(21.8)$ \\
\hline Emotional abuse & & & $34(16.5)$ \\
Should not be tolerated at all & $14(15.6)$ & $20(17.2)$ & $131(63.6)$ \\
Should be tolerated sometimes & $55(61.1)$ & $76(65.5)$ & $41(19.9)$ \\
Should be tolerated all the time & $21(23.3)$ & $20(17.2)$ & $57(29.4)$ \\
\hline Sexual abuse & & & $92(47.4)$ \\
Should not be tolerated at all & $17(21.5)$ & $40(34.8)$ & $45(23.2)$ \\
Should be tolerated sometimes & $39(49.4)$ & $53(46.1)$ & \\
Should be tolerated all the time & $23(29.1)$ & $22(19.1)$ & \\
\hline
\end{tabular}

the study population consisted of those aged between $30-49$ years. A large proportion $(84.7 \%$ ) were housewives. The majority of the participants as well as their husbands were educated up to GCE (Ordinary Level).

\section{Prevalence of abuse}

Some form of abuse by the husband was experience by $98(40.5 \%)$ of the study population during the period of their marital relationship. Of them, $46(19 \%)$ had been physically abused, $56(23 \%)$ had been verbally abused, $55(22.7 \%)$ had been emotionally abused and $18(7 \%)$ had been sexually abused.

Response to abuse in $64 \%$ of the abused was to tolerate it without resistance. However, 19\% responded by leaving home while $16 \%$ admitted they retaliated verbally. None admitted to physical retaliation.

Twelve participants of the study needed hospitalization for abuse. Only two of them have reported to the health staff that injuries were caused by their partners.

\section{Attitude towards abuse}

Table 1 compares attitude towards abuse by abused (those who experienced any form of abuse) and nonabused. Responding to a question 'should wives tolerate abuse?" the participants chose one of three responses 'all the time' 'sometimes' or 'never'. A majority thought that abuse of all forms should be tolerated 'sometimes'. Only a minority thought it should never be tolerated (Table 1). Not all participants responded to this question and even when they did, they did not respond to the question in all four categories: physical, verbal, emotional and sexual

When the abused and non- abused groups were considered separately, $30 \%$ of the abused thought physical violence should be tolerated all the time as opposed to $19 \%$ of the non- abused $\left(\chi^{2}=3.57, \mathrm{df}=1, \mathrm{p}=0.06\right.$, ). This difference was not significant. The difference with regard to sexual abuse however was significant and $35 \%$ of the non- abused felt it should not be tolerated at all while only $21 \%$ of the abused felt so $\left(\chi^{2}=3.97\right.$, $\mathrm{df}=1, \mathrm{p}=0.046)$.

\section{Alcohol use}

Of the abused, $61.2 \%$ reported that their partners used alcohol and other substances. This was significant compared to the $19.21 \%$ of the non-abused who reported same $\left(\chi^{2}=45.6 ; \mathrm{df}=1 \mathrm{p}<0.001\right)$. The majority of both the abused as well as the non- abused stated that alcohol and other substance abuse was the main cause of conflicts in the relationship.

\section{Marital relationship}

Of those abused, $79 \%$ had been married for more than 10 years. However the overall relationship was poorer in the abused group as measured by a Likert scale. Of those abused, $18 \%$ described the relationship as poor or very poor, compared to only one in the nonabused group (Yates $\chi^{2}=22.8, \mathrm{df}=1, \mathrm{p}<0.001$ ). Of the abused $31.4 \%$ reported that abuse was witnessed by the children.

\section{Discussion}

Our study showed a high prevalence of IPV which was within the range of prevalence shown in studies carried out in other countries $(3,5,6)$. Verbal abuse and emotional abuse were the more frequent forms, as shown in other studies. Hospital based studies show higher prevalence of IPV(7).

It is interesting that the majority have responded to abuse by tolerating it without resistance. This could be due to a culturally accepted submissive role of 
women. It is noteworthy that $79 \%$ of those who have been abused have stayed in the relationship for more than 10 years. Although the study did not explore the reasons behind this, it may be reasonable to assume that social and financial reasons may have contributed to this phenomenon The stigma attached to a woman leaving the marriage and financial dependence on the male are factors that greatly influence separation. In a study carried out in the Trincomalee district in the Eastern province of Sri Lanka, it was shown that most women, regardless of their level of education and their employment status, considered the welfare of their children as a prime reason for staying in an abusive relationship (8).

\section{Associations with violence}

Children of $31 \%$ of the victims in our study witnessed violence inflicted on their mother by the fathers. This may have far reaching implications. Violence against women is considered to have an inter-generational cycling (9). It is thought that men, who as children have witnessed violence at home, will accept it as the norm. They are more likely to abuse their intimate partners (10). Women who as children witness violence against their mother are more likely to tolerate violence by their partners and respond in a passive manner. It is possible therefore that in the future these silent observers themselves will be victims or perpetrators of abuse and play a role in propagating IPV.

Abuse of alcohol by the spouse was seen in a majority of the abusers. It has been suggested that most men use alcohol as a cultural "time out" for antisocial behaviour. Alcohol is used as an excuse to abuse their partners as they are not held responsible for what they do when they are intoxicated. The role of alcohol in IPV in Asian societies has been highlighted in other studies (5).

Intimate partner violence has a significant impact on health and gives rise to long lasting health consequences (11). Women who have experienced IPV have more depressive symptoms than women who have not $(12,13)$. Common mental disorders in the Indian subcontinent are shown to be associated with recent domestic IPV (14). Severe IPV can lead to post traumatic stress disorder (PTSD) (15).

\section{Limitations}

The main limitation of the study is that it was a hospital based study and the community prevalence of IPV may be different. We also confined ourselves to married females and have not included unmarried or cohabiting females who may be abused by their boyfriends or partners. The frequency and severity of abuse was also not assessed.

\section{Implications}

It is important that awareness about domestic violence is raised, emphasizing that abuse of any form should not be tolerated. Education at all levels is needed to change the attitudes that perpetuate violence. Screening for IPV is generally lacking worldwide. Kramer et al (7) showed that only $25 \%$ of a sample of primary care patients reported being screened for violence, although $83 \%$ supported the idea. Only 2 out of the 12 that needed medical care for their injuries, revealed to the medical staff, that the injuries were as a direct result of IPV. In a recent study in New Zealand less than half of those who sought treatment for injuries reported IPV (16). Under reporting appears to be a problem in all parts of the world and studies reveal that most cases of domestic violence are not identified by doctors (17). The reason why doctors do not screen women for IPV could simply be that they are not trained to do so and are unsure how to do it. Raising awareness among doctors about IPV and training them on proper screening techniques appears to be an important need (18). Educating women about their rights and providing them with legal and psychological support will also contribute towards combating IPV.

\section{Declaration of interest}

None

K.A.L.A.Kuruppuarachchi, MD, FRCPsych, Professor L.T.Wijeratne, MBBS, MD (Psych), Lecturer G.D.S.S.K.Weerasinghe, MBBS, Demonstrator M.U.P.K.Peris, MD(Psych), MRCPsych, Senior Lecturer S.S.Williams MD(Psych), MPhil, MRCPsych, Senior Lecturer Department of Psychiatry, Faculty of Medicine, University of Kelaniya,Sri Lanka

\section{Corresponding author}

S.S.Williams, Department of Psychiatry, Faculty of Medicine, University of Kelaniya, Sri Lanka

Email:shehanwil@msn.com

\section{References}

1. Heise L, Garcia-Moreno C. Violence by intimate partners. In:Krug EG, Dahlberg LL, Mercy JA, et al, eds. World report on violence and health. Geneva, World Health Organization, 2002.

2. Garcia-Moreno C, Jansen HAFM, Ellsberg M, Heise L, Watts C. WHO Multi-country Study on Women's Health and Domestic Violence against Women. Initial results on prevalence, health outcomes, and women's responses. Geneva, World Health Organization, 2005.

3. Garcia-Moreno C, Jansen HA, Ellsberg M, Heise L, Watts $\mathrm{CH}$; WHO Multi-country Study on Women's Health and Domestic Violence against Women Study Team. Prevalence of intimate partner violence: findings from the WHO multi-country study on women's health and domestic violence. Lancet. 2006 Oct 7;368(9543):12609.

4. Ministry of Justice and Law Reforms. Ministry of Justice and Law Reforms of Sri Lanka. New legislation. Prevention of domestic violence act: Act No. 34 of 2005. http://www.justiceministry.gov.lk/

5. Jeyaseelan L, Kumar S, Neelakantan N, Peedicayil A, Pillai R, Duvvury N. Physical spousal violence against women in India: some risk factors. J Biosoc Sci. 2007 Sep;39(5):657-70. 
6. Raj A, Silverman JG. Intimate partner violence against South Asian women in greater Boston. J Am Med Womens Assoc. 2002 Spring;57(2):111-4.

7. Kramer A, Lorenzon D, Mueller G. Prevalence of intimate partner violence and health implications for women using emergency departments and primary care clinics. Womens Health Issues. 2004 JanFeb;14(1):19-29.

8. Subramanium P, Sivayogan S. The prevalence and pattern of wife beating in the Trincomalee District in eastern Sri Lanka. Southeast Asian J Trop Med Public Health. 2001; 32:186-195.

9. Bensley L, Van Eenwyk J, Wynkoop Simmons K. Childhood family violence history and women's risk for intimate partner violence and poor health. Am J Prev Med. 2003 Jul;25(1):38-44.

10. Roberts AL, Gilman SE, Fitzmaurice G, Decker MR, Koenen KC. Witness of intimate partner violence in childhood and perpetration of intimate partner violence in adulthood. Epidemiology. 2010 Nov;21(6):809-18.

11. Ellsberg M, Jansen HA, Heise L, Watts $\mathrm{CH}$, GarciaMoreno C; WHO Multi-country Study on Women's Health and Domestic Violence against Women Study Team. Intimate partner violence and women's physical and mental health in the WHO multi-country study on women's health and domestic violence: an observational study. Lancet. 2008 Apr 5;371(9619):1165-72.
12. Bonomi AE, Thompson RS, Anderson M, Reid RJ, Carrell D, Dimer JA, Rivara FP. Intimate partner violence and women's physical, mental, and social functioning. Am J Prev Med. 2006 Jun;30(6):458-66.

13. Kumar S, Jeyaseelan L, Suresh S, Ahuja RC. Domestic violence and its mental health correlates in Indian women. Br J Psychiatry. 2005 Jul;187:62-7.

14. Shidhaye R, Patel V. Association of socio-economic, gender and health factors with common mental disorders in women: a population-based study of 5703 married rural women in India. Int J Epidemiol. 2010 Oct 29.

15. Lilly $\mathrm{MM}$, Graham-Bermann SA. Intimate partner violence and PTSD: the moderating role of emotionfocused coping. Violence Vict. 2010;25(5):604-16.

16. Fanslow JL, Robinson EM. Physical injuries resulting from intimate partner violence and disclosure to healthcare providers: results from a New Zealand population-based study. Inj Prev. 2010 Sep 28.

17. Bansal SK, Park E, Edwardsen EA. Medical inquiry for intimate partner violence as reported by women in a shelter. J Emerg Med. 2008 Apr;34(3):341-5.

18. Moonesinghe LN, Rajapaksa LC, Samarasinghe G. Development of a screening instrument to detect physical abuse and its use in a cohort of pregnant women in Sri Lanka. Asia Pac J Public Health. 2004; 16:138-144. 